\title{
Demographic Predictors of Work-Family Conflict for Men and Women: The Case of Nigeria
}

\author{
Chris Adalikwu (Corresponding author) \\ College Of Business, Hankuk University Of Foreign Studies, 270-Imundong, \\ Dongdaemun-gu, Seoul-130-791, KOREA. \\ E-mail: akwa22000@yahoo.com
}

Received: September 18, 2013 Accepted: September 28, 2013 Published: December 8, 2013

doi:10.5296/rbm.v1i1.4696

URL: http://dx.doi.org/10.5296/rbm.v1i1.4696

\begin{abstract}
This study investigates the impact of several demographic factors (gender, age, marital status, and position, number of children and employment of the spouse) on work-family conflict and family-work conflict. The study includes the employees in manufacturing and service sectors in Lagos. According to the results in this study, the level of work-family conflict of males and females is high, and no statistically meaningful difference is found between their means. Logistic regression analysis shows that the log of odds of males experiencing work-family conflict is negatively correlated with education and job tenure, but positively correlated with marital status. The log of odds of females experiencing work-family conflict is negatively correlated with education whereas it is positively correlated with marital status. Job tenure has an impact on family-work conflict of males, and age of children and having to care elderly parents are noted to have an impact on family-work conflict of females.
\end{abstract}

Keywords: work-family conflict, family-work conflict, demographic factors, logistic regression, Nigeria

\section{Introduction}

Similar to the case in many other countries, Nigeria has also experienced several changes in female employment participation and the number of couples with double career has been increasing in the past twenty years (Hammer, Neal, \& Kuang, 2005; Harvey \& Breland, 2009). Considering the most recent statistics, female employment participation rate was $20.3 \%$ in 2004, and it reached $28.8 \%$ in 2011 (TUTULA, 2011). This change has led to a significant variation in the number and variety of family roles (spouse, parent and/or caretaking of the elderly) undertaken by the employees (Car1kc1, 2001). In accordance with the trends in demographic changes, transformation has been noted in traditional roles, as a result of which interest in such issues as gender differences of males and females who are overloaded in their roles and who experience work-family conflict, and psychological 
well-being has been increasing (Aycan \& Eskin, 2005; Innstrand, Langballe, Falkum, Espnes, \& Aasland, 2009).

Literature related to work-life conflict states that the conflict between work and family domains is bidirectional. While work is in conflict with family domain, family is also in conflict with work domain. It is noted that in work-family conflict (WFC), work requirements conflict with the performance of family responsibilities, and in family-work conflict (FWC), family demands conflict with the performance of work responsibilities (Willis, O'Conner, \& Smith, 2008; Maertz \& Boyar, 2011). Several studies have been carried out in recent years about the antecedents and consequences of the conflict between work and family roles (e.g. Cinamon \& Rich, 2005; Michel, Mitchelson, Kotrba, LeBreton, \& Baltes, 2009; Powell \& Greenhaus, 2010). Failure in balancing two vital components of life, namely work and family, is likely to lead to increase in WFC. Research indicates that WFC brings about numerous negative outcomes in work and family domains, some of which are exhaustion, anxiety, high blood pressure, low satisfaction from marriage, poor role performance, low professional well-being, life dissatisfaction, low organizational commitment, work dissatisfaction, burnout, desire to quit and high turnover (Willis et al., 2008; Maertz \& Boyar, 2011).

Both topics of WFC, and causes and consequences of WFC are attracting the attention from human resources and organizational behavior scholars recently (Marchese, Bassham, \& Ryan, 2002). The most important reason why these topics are attracting so much attention is that FWC and WFC negatively affect the performance of individuals and organizations. Poelmans (2001) mentions absence of empirical studies about WFC in cultures in which family is a powerful institution and in which women employment tends to increase. Therefore, it is important to identify the level of WFC and FWC of male and female employees with respect to their demographic features in Nigeria, a country with a cultural structure of eastern and western synthesis, and where family is considered a significant institution and where more and more females participate in labor force.

Furthermore, male and female employees are expected to have different levels of WFC experience with respect to their demographic features (education, marital status, age, age of children, caretaking of the parents), considering the difference between males and females in the perception of WFC due to their different roles in the workplace and at home. Therefore, it is believed that a detailed study of demographic features that cause WFC and FWC in terms of gender, which constitutes the basic aim of this study, will fill the gap in the related literature. Moreover, the fact that this study includes a great many male and female employees from various sectors, a quality which makes it different from other studies, will enable the results to be generalized.

\section{Literature Review and Research Hypotheses}

WFC and FWC occur when one needs to deal with the demands of work and family domains simultaneously. The findings of studies about the effect of gender on WFC are complicated and it should never be considered simple (Voydanoff, 2002; Powell \& Greenhaus, 2010). While some studies state that females experience WFC more often and at a higher level, some others indicate it has no impact at all (Frone, 2003; Akintayo, 2010). According to gender 
role theory, females are more likely to consider the family role as a component of social identity compared to males. Furthermore, expectations from females considering their family role do not decrease although responsibilities regarding their roles in the workplace keep increasing. Therefore, compared to males, females are more likely to display a negative attitude towards work when their work conflicts with family since they regard work as a threat to their main social role. However, according to gender role theory, when work conflicts with family, such a conflict is unlikely to cause males to change their attitude towards work (Grandey, Cordeiro, \& Crouter, 2005; Baral \& Bhargava, 2010). Males tend to feel less guilty conscious than females since the conflict they experience does not harm their social identity much, as a result of which their perception of WFC is different from that of females (Burke \& El-Kot, 2010; Hassan, Dollard, \& Winefield, 2010). Hence, the below stated hypothesis has been proposed within the scope of gender theory.

\section{H1. Females experience more work-family conflict than males.}

WFC is considered as the less studied dimension of the conflict process. However particularly in recent years WFC which is another dimension of WFC is began to be studied with the entrance of this topic into the human resources management and organizational behavioral literature. Previously, causes of individual's low work performance level or individual's work-related inefficiencies were only examined in work-related factors however with the gaining importance of FWC it is accepted that individual's family-related features may also affect work performance. Besides one of the important reasons of examining FWC as much as WFC can be understood with realizing WFCs are not only woman employees' but also all employees' problem. Collective Nigerian society is generally family-focused, and in such a traditional society, the primary role of males is bread winner while that of females is taking care of the family as a faithful wife, mother and sister. Females take on more responsibilities than males to fulfill family commitments, which is also valid among Nigerian families in which both partners are educated and have careers. Although it may conflict with social and professional activities of females, wives are expected to take on responsibilities about family matters. On the other hand, limited participation in family matters are expected from husbands (Foley, Huang-yue, \& Lui, 2005; Craig \& Sawrikar, 2009). Males and females are supposed to perform different duties based on gender differences, which is a culture oriented case. The below stated hypothesis has been proposed with the assumption that females experience a higher level of FWC compared to males in more traditional, homogenous, hierarchic and collective focused Nigerian society.

\section{H2. Females experience more family-work conflict than males.}

When the related literature is investigated, it is noted that individual variables such as gender, marital status and number of children have an impact on WFC (Cinamon \& Rich, 2005; Michel et al., 2009). Woman's role and position in the family and society should be considered together with her duties as a mother and wife since this is a centuries-long-rooted conception in society. It could be claimed that work and family conflict is created by the double role of the working woman, as a mother and wife. Each role needs time devotion, which creates a heavy burden for the woman causing roles to be mixed up. Social 
transformation experienced by females is significant in this respect. Beyond woman's traditional responsibilities as a mother and wife, how independent she could be stands out. Though there may be changes in different countries, before all else, Nigerian women are expected to undertake their social roles as a mother and wife; and professional success and career remain in the second place (Lagoslı \& Carıc1, 2007).

Considering traditional role theory, women, and even men to a certain extent, need to spare more time to housekeeping chores and family commitments especially after they get married compared to singles (Carıkcı \& Celikkol, 2009). Coffey, Anderson, Zhao, Liu, and Zhang (2009) states that such specific aspects of family structure as marriage and care of parents cause work-family conflict to increase. Women share the responsibility of keeping a family with their husbands; however, husbands fail to share the responsibility of sharing housekeeping chores. Despite the fact that husband's help in housekeeping chores reduces women's work load to some extent, work load mainly remains to be the responsibility of woman (Lagoslı \& Carıkc1, 2007). The below stated hypotheses are proposed in this respect.

H3a. Married men experience more work-family conflict compared to single men.

H3b. Married women experience more work-family conflict compared to single women.

Experiencing WFC may prevent the employees from performing their family responsibilities and family commitments that are important for their aims in the family domain (sparing more time for children and elderly parents). It is stated in the related literature that such variables as number of children, age of children, parents in need of care and both spouses working have an impact on WFC, and findings indicate that these factors are among the significant causes of WFC (Greenhaus \& Beutell, 1985; Frone, Russell, \& Barnes, 1996). Though slowly, females have been making progress in the last 20 years. However, despite having a career, they are still mainly in charge of housekeeping chores and child care (Forster, 2001; $\mathrm{Ng}$, Fosh, $\&$ Naylor, 2002). On the other hand, when a man has a working wife and children, or when he is a single parent who is in charge of child care, he has to cope with more family responsibilities (Huffman, Payne, \& Castro, 2003). The below stated hypotheses are proposed in this respect.

H4a. Number of children has an impact on work-family conflict and family-work conflict of males.

H4b. Number of children has an impact on work-family conflict and family-work conflict of females.

Having children at the pre-school age is likely to affect the employment of especially females, and therefore, expectations about male and female employment tend to be different (Kinnunen \& Mauno, 1998). Thus, FWC may be different for each gender. Having children, especially those at pre-school age, who demand considerable time devotion is expected to be positively correlated with FWC with no gender discrimination. Hypotheses H6a and H6b are proposed in this respect. 
H5a. Males with children at pre-school and school-age experience more family-work conflict than those with children at post-school age.

H5b. Females with children at pre-school and school-age experience more family-work conflict than those with children at post-school age.

Family demands and responsibilities are a significant factor that affects the ability to balance work and family demands. Both females and males have to deal with conflict which is constantly increasing as they attempt to fulfill the demands and responsibilities of work and family roles (Taber \& Alliger, 1995). Boles, Johnston, and Hair (1997), propose that WFC is not limited to marital status, adding that mothers and fathers may face difficulties in balancing work and family domains due to work, children and care of elderly parents. Also, increasing female employment and increasing number of the elderly who need care contribute to the conflict between work and family roles (Boyar, Maertz, \& Pearson, 2005). Besides, in collectivist societies, individuals like getting family support and also they are ready to provide support to the elderly parents, and take on such a responsibility in addition to other family responsibilities (Spector et al., 2007). The below stated hypotheses are proposed based on this acquirements.

H6a. Males who need to take care of parents experience more family-work conflict compared to those who do not need to do so.

H6b. Females who need to take care of parents experience more family-work conflict compared to those who do not need to do so.

Another demographic characteristic that has an impact on WFC is the level of education. Education level of some employees may reinforce their role outside the family and increase organizational commitment. Those with higher education may have the opportunity to be promoted and to be posted to another location. When accepted, such benefits may create WFC as they need to take on more responsibilities increasing their work commitment

(Carnicer, Sánchez, \& Pérez, 2004). Most recent research results of NISS (2006) indicate that family relations of university graduates and post-graduates tend to be on the downgrade compared to those of high school graduates.

The below stated hypotheses are proposed in this respect.

H7a. As the level of education increases, males experience more work-family conflict.

$H 7 b$. As the level of education increases, females experience more work-family conflict.

In their studies investigating the boundaries between family and work, Eagle, Miles, and Icenogle (1997) revealed that professional boundaries are not much penetrable whereas family boundaries are (Kasper, Meyer, \& Schmidt, 2005). Many managers may be affected by the relation between their professional and private life. For example, managers may often experience lack of time, energy and attention since inquiring and analyzing knowledge during decision-making process is a complicated and time-consuming task. When the conflict between work and family domains limits the decision-making process, important decisions 
about work domain may not be taken correctly or timely (Coffey, et al.,2009). As well as managerial career, long and irregular working hours is also closely related to WFC. Managerial career requires full time support of the family and the spouse (Schmidt \& Duenas, 2002). Especially female managers tend to lack full time support of the spouse and therefore, their managerial career increases difficulties which they experience. It is expected that those with managerial careers experience more WFC compared to those without a managerial post. The below stated hypotheses are proposed in this respect.

H8a. Male managers experience more work-family conflict and family-work conflict compared to other employees.

H8b. Female managers experience more work-family conflict and family-work conflict compared to other employees.

Another factor that may have impact on the level and direction of the conflict is job tenure of the employee. Both for males and females, longer job tenure helps deal with work demands without being much affected by family responsibilities since experience equips them with necessary professional excellence and adaptability (Cinamon \& Rich, 2005). Furthermore, it is stated that experience and competence obtained throughout time help employees develop formal and informal strategies to overcome problems created by WFC and FWC. The below stated hypotheses are proposed in this respect.

H9a. Males with longer job tenure experience more work-family conflict and family-work conflict compared to those with less job tenure.

H9b. Females with longer job tenure experience more work-family conflict and family-work conflict compared to those with less job tenure.

Basic work demands as well as household responsibilities of both males and females have increased as a result of increase in the number of couples each with a career and also as a result of changes in family and workforce, such as working mothers (Cinamon \& Rich, 2005). The most significant demographic change in Nigeria seen in recent years is increasing level of education, which has paved the way especially for females to have a career and to become mother at a later age. Such a trend means moving from families with double income to families with double career (Kapız, 2002). Elloy (2004) proposes that when both partners are working, this is a cause of work-family conflict. Level of FWC increases in families in which both partners have full time or part time jobs as they face two separate types of demands from work and family domains (Fu \& Shaffer, 2001; Voydanoff, 2002). Therefore, employment status of the spouse, especially if he/she has a paid work, has a significant impact on FWC. In relation to previous studies, the below stated hypotheses are proposed.

H10a. Men whose wives have a job experience more family-work conflict than those whose wives do not.

H10b. Women whose husbands have a job experience more family-work conflict than those whose husbands do not. 


\section{Data and Method}

\subsection{Sample and Procedure}

Respondents in this study are the employees in manufacturing and service sectors in Lagos, a high-ranking city considering population density. Data in this study has been collected through questionnaires. Human Resource Department of each organization conducted the distribution and collection of questionnaires. In several other studies, data about work-family conflict was generally collected from the employees of one organization, or from organizations in the same sector. The sampling in this study is composed of employees with various careers and from different sectors in order to ensure generalization of the results. The fact that data in this study is collected from different organizations in various sectors shall provide better external validity and higher level of generalizability (Cook \& Campbell, 1979), besides previously carried out studies in the field are expected to be improved.

Data in this study has been collected from the employees of 20 organizations, registered in Chamber of Commerce and Industry of Lagos, chosen randomly among the top 100 organizations with respect to number of staff. Scope of business of the organizations in the sampling is textile, machinery, chemistry, food production, tourism and health. Both blue-collar workers and white-collar workers are included in this study. 20 organizations which participated in this study have a total of around 2600 employees. Each organization has been given as many questionnaires as their number of employees and a total of 800 usable ones have turned back. The return rate of the questionnaires from organizations is between $25 \%$ and $30 \%$.

\subsection{Measures}

The questionnaire is composed of two parts. In the first part, eleven-item work-family conflict and family-work conflict scale developed with the help of work spillover measures of Grandey, Cordeiro, and Crouter (2005), and Small and Riley (1990) is used. Responses to the six WFC items and the five FWC items were made on a Likert-type scale ranging from 1 (strongly disagree) to 5 (strongly agree). In the second part of the questionnaire, demographic questions such as gender, age, marital status and professional status, and family domain variables such as number of children, number of dependents and employment status of the spouse are found. The reliability of WFC and FWC scales was measured with Cronbach alpha. Cronbach alpha for WFC and FWC was .86 and .83 , respectively.

To examine the factor structures of the WFC and FWC scale, confirmatory factor analysis (CFA) using LISREL 8 (Jöreskog \& Sörbom, 2001) was employed. We began by testing a single factor, eleven items model, labeled Model1. Model2 is two factor models. Goodness of fit indices related to these models is reported in Table 1. The two factor model (Model 2) of WFC and FWC provides good fit as compared to the single factor model (Model 1). All fit indices for the single factor model are poor. The $\chi 2$ of 256.75 (35), $p=.000$ is quite high and significant. The AGFI of .42 suggests the model parsimony is poor. Model 2 provides improved fit. 


\section{Macrothink}

The $\chi^{2}$ of 32.09 (29), $\mathrm{p}=.31$ is non-significantly lower. The AGFI=.89, TLI=.99. In such a case, WFC and FWC could be said to be two separate constructs. Hence, WFC and FWC are considered as separate constructs in this article.

Table 1. Model fit

\begin{tabular}{|l|l|l|l|l|l|l|}
\hline Model & \multicolumn{4}{|l|}{ Absolute fit indices } & Incremental fit & Parsimonious fit \\
\hline & Df & $\chi 2$ & GFI & RMR & TLI & AGFI \\
\hline Mode11 & 35 & 256.75 & 66 & .13 & .63 & .42 \\
\hline Mode12 & 29 & 32.09 & .94 & .04 & .99 & .89 \\
\hline
\end{tabular}

\subsection{Dependent Variables}

Table 2. Cluster descriptors: differences in mean values for work- family conflict and family-work conflict

\begin{tabular}{|l|l|l|l|}
\hline Conflict & Cluster 1 & \multicolumn{2}{|l|}{ Cluster 2 } \\
\hline Work-family conflict (male) & $\begin{array}{l}\text { Mean (percent) } \\
3.92(61.8 \%)\end{array}$ & $\begin{array}{l}\text { Mean (percent) } \\
2.23(38.2 \%)\end{array}$ & $\begin{array}{l}\mathrm{t} \\
3.64 *\end{array}$ \\
\hline Work-family conflict (female) & $4.09(51.3 \%)$ & $2.56(48.7 \%)$ & $4.02^{*}$ \\
\hline Family-work conflict (male) & $3.60(33.8 \%)$ & $1.89(66.2 \%)$ & $3.44^{*}$ \\
\hline Family-work conflict (female) & $3.90(36.4 \%)$ & $2.05(63.6 \%)$ & $3.35^{*}$ \\
\hline
\end{tabular}

$* \mathrm{p}<.01$.

Work- family conflict and family-work conflict are undertaken as dependent variables in this study. Cluster analysis is applied to transform these two metric variables into categories, the findings of which are given in Table 2. Two clusters are formed as a result of the cluster analysis for work-family conflict and family-work conflict.

Those in the first cluster are the ones who experience work-family conflict and family-work conflict, and they were coded as 1 in the dependent variable. Those in the second cluster are 
the ones who do not experience work-family conflict and family-work conflict, and they were coded as 0 in the dependent variable. Dependent variable has a discriminative feature since there is a statistically meaningful difference between Cluster 1 and Cluster 2 (see Table 2).

\subsection{Independent Variables}

Age, marital status, parents who need care, number of children, age of children, education, job tenure, employment of the spouse and status are considered as independent variables in this study. Binary logistic regression analysis is used to determine which of the independent variables have an impact on work-family conflict and family-work conflict because dependent variables have two categories that cannot be ranked. We estimate separate models for men and woman so that all of the coefficient are free to vary by gender and thus reveal any gender differences in the determinants of work-family conflict and family-work conflict.

$45.1 \%$ of the respondents are males, and $54.9 \%$ are females. The rate of those who are married is $60.6 \%$, that of singles is $35.1 \%$, and the rate of those who are divorced is $4.3 \%$. $26.1 \%$ of the respondents have one child, and $29.6 \%$ have two or more children. $44.3 \%$ of the respondents do not have children. Children of $22.4 \%$ of the respondents with children are at pre-school age. The rate of those with children at pre-school and school age is $14.9 \%$. $25.4 \%$ of the respondents have parents whom they need to care. $37.3 \%$ of the respondents are high school graduates, $22.9 \%$ have a two-year degree, and 39.9\% are university graduates. $76.9 \%$ of the respondents are employees with no managerial status and almost half of them $(53.3 \%)$ have less than 6 years of work experience. Spouses of $22.6 \%$ of the respondents do not work while those of $46.9 \%$ have full time employment.

\section{Results}

$\mathrm{T}$ test has been carried out to see if there is a difference between work-family conflict and family-work conflict of males and females (see Table 3). Work-family conflict of both males and females is high and there is no statistically meaningful difference between males and females. Therefore, Hypothesis 1 proposing females experience more work-family conflict than males is rejected. While both genders have low levels of family-work conflict, females are noted to experience more family-work conflict than males. Thus, Hypothesis 2 that proposes females experience more family-work conflict than males is accepted.

Table 3. The effects of gender on work-family conflict and family-work conflict

\begin{tabular}{|l|l|l|l|l|}
\hline & Female (439) & Male (361) & $\mathrm{t}$ & $\mathrm{p}$ \\
\hline Work-family conflict & 3.34 & 3.27 & -0.99 & 0.321 \\
\hline Family-work conflict & 2.73 & 2.47 & 2.86 & $0.000^{*}$ \\
\hline
\end{tabular}

$* \mathrm{p}<.01$. 


\section{Macrothink Institute ${ }^{\mathrm{TM}}$}

Four logistic regression analyses based on gender have been carried out investigate the hypotheses in the study. In two of them, work-family conflict is the dependent variable (see Table 4), and in the other two, dependent variable is family-work conflict (see Table 5).

These four models fit to the data appropriately. In Table 4, Hosmer-Lemeshow value is 4.224 for men, and 14.433 for women. In Table 5, Hosmer-Lemeshow value is 5.814 for men, and 10.996 for women. Overall accuracy rate varies between $70.4 \%$ and $78.6 \%$. Table 4 states that the $\log$ of the odds of work-family conflict of men is negatively correlated with education and work experience while it is positively correlated with marital status $(p<.05)$.

The log of the odds of work-family conflict of women is negatively correlated with education while it is positively correlated with marital status $(p<.05$; Table 4$)$. Variables that have an impact on family-work conflict of females are different from those of males.

Table 4. Logistic Regressions predicting work-family conflict by gender

\begin{tabular}{|c|c|c|c|c|c|c|}
\hline \multirow[t]{2}{*}{ Independent variables (code) } & \multirow[b]{2}{*}{ B } & \multicolumn{2}{|l|}{ Men } & \multicolumn{3}{|c|}{ Women } \\
\hline & & Wald's $\chi^{2}$ & $\operatorname{Exp}(B)$ & B & Wald's $\chi 2$ & $\operatorname{Exp}(B)$ \\
\hline \multicolumn{7}{|l|}{ Marital Status } \\
\hline Married (1) & 2.494 & $12.869 * *$ & 12.105 & 2.970 & $14.131 * *$ & 19.484 \\
\hline \multicolumn{7}{|l|}{ Single (2) RG } \\
\hline Number of Children & & 3.872 & & & .122 & \\
\hline No child (1) & -1.074 & .865 & .342 & .998 & 2.561 & 2.619 \\
\hline One child (2) & .812 & 3.750 & .444 & .152 & .122 & 1.164 \\
\hline \multicolumn{7}{|l|}{ Two or more children (3) RG } \\
\hline Age of Children & & 3.034 & & & .646 & \\
\hline All at pre-school age (1) & .733 & 1.313 & 2.080 & .815 & 1.513 & 2.313 \\
\hline At pre-school \& school age(2) & .936 & 1.587 & 2.549 & .261 & .114 & 1.299 \\
\hline All at school age (3) & .119 & .031 & 1.126 & -.067 & .009 & .939 \\
\hline
\end{tabular}




\begin{tabular}{|c|c|c|c|c|c|c|}
\hline $\begin{array}{l}\text { At school and post-school age- } \\
\text { (4) }\end{array}$ & .065 & .009 & .937 & .318 & .203 & 1.374 \\
\hline \multicolumn{7}{|l|}{ At post-school age (5) RG } \\
\hline \multicolumn{7}{|l|}{ Having parents who need care } \\
\hline Yes (1) & .072 & .037 & 1.074 & .571 & 2.887 & 1.769 \\
\hline \multicolumn{7}{|l|}{ No (2) RG } \\
\hline Education & & $11.850^{* *}$ & & & $10.607^{* *}$ & \\
\hline Elementary and Secondary (1) & .424 & .887 & 1.528 & -.872 & $4.416^{*}$ & .423 \\
\hline Two-year degree (2) & -.966 & $7.043^{*}$ & .381 & -.189 & $9.496 * *$ & .303 \\
\hline \multicolumn{7}{|l|}{ University (3) RG } \\
\hline \multicolumn{7}{|l|}{ Status } \\
\hline Manager (1) & .283 & .477 & 1.327 & .265 & .638 & 1.303 \\
\hline \multicolumn{7}{|l|}{ Employee (2) RG } \\
\hline \multicolumn{7}{|l|}{ Job Tenure } \\
\hline 5 years or less (1) & -.312 & $9.818^{* *}$ & .269 & -.028 & .004 & .973 \\
\hline \multicolumn{7}{|l|}{6 years or more (2) RG } \\
\hline Employment of the Spouse & & 4.023 & & & 1.132 & \\
\hline Working part-time (1) & -.811 & .032 & 1.119 & -.438 & .388 & .645 \\
\hline Working full-time (2) & .672 & 3.836 & 1.958 & .178 & .151 & 1.195 \\
\hline \multicolumn{7}{|l|}{ Not working (3) RG } \\
\hline Hosmer and Lemeshow Test & & 4.224 & & & 14.433 & \\
\hline
\end{tabular}




\begin{tabular}{|l|l|l|l|l|l|l|}
\hline (Che-square) -2LL & & & & & & \\
\hline & & 279.207 & & & 10.727 & \\
\hline Cox \& Snell R Square & & .199 & & & .201 & \\
\hline Nagelkerke R Square & & .271 & & & .270 & \\
\hline Classification Percent & & $74.5 \%$ & & & $70.4 \%$ & \\
\hline $\mathrm{N}$ & & 361 & & & $439-$ & \\
\hline
\end{tabular}

${ }^{*} \mathrm{p}<.05,{ }^{* *} \mathrm{p}<.001 \mathrm{RG}$ : reference group.

Logistic regression model in which family-work conflict is considered as dependent variable indicates that only job tenure affects family-work conflict of males whereas age of children and parents whom they need to care affect family-work conflict of females (see Table 5). It is less likely for a man to be within the group experiencing work-family conflict as he gets older.

Table 5. Logistic regressions predicting family- work conflict by gender

\begin{tabular}{|c|c|c|c|c|c|c|}
\hline \multirow[t]{2}{*}{ Independent variables (code) } & \multicolumn{3}{|l|}{ Men } & \multicolumn{3}{|c|}{ Women } \\
\hline & $\mathrm{B}$ & $\begin{array}{l}\text { Wald' } \\
\chi^{2}\end{array}$ & $\operatorname{Exp}(B)$ & $\mathrm{B}$ & $\begin{array}{l}\text { Wald' } \\
\chi^{2}\end{array}$ & $\operatorname{Exp}(B)$ \\
\hline \multicolumn{7}{|l|}{ Marital Status } \\
\hline Married (1) & .101 & .012 & 1.106 & .733 & .623 & 2.082 \\
\hline \multicolumn{7}{|l|}{ Single (2) RG } \\
\hline Number of Children & & 3.016 & & & .029 & \\
\hline No child (1) & -.330 & .097 & .719 & .812 & 1.962 & 2.315 \\
\hline One child (2) & -.680 & 2.983 & .506 & .132 & .142 & 1.216 \\
\hline Two or more children (3) RG & & & & & & \\
\hline
\end{tabular}




\begin{tabular}{|c|c|c|c|c|c|c|}
\hline Age of Children & & 2.357 & & & $3.562 *$ & \\
\hline All at pre-school age (1) & .695 & .303 & 2.004 & .985 & 1.513 & 1.313 \\
\hline At pre-school and school age (2) & -.605 & .618 & .546 & 1.693 & $5.114 *$ & 5.433 \\
\hline All at school age (3) & .829 & 1.489 & 2.292 & -.089 & .016 & .915 \\
\hline At school and post-school age (4) & .667 & .942 & .949 & -.941 & 1.749 & .390 \\
\hline \multicolumn{7}{|l|}{ At post-school age(5) RG } \\
\hline \multicolumn{7}{|l|}{ Having parents who need care } \\
\hline Yes (1) & .297 & .789 & 1.345 & .873 & $7.470 * *$ & 2.393 \\
\hline \multicolumn{7}{|l|}{ No (2) RG } \\
\hline Education & & 3.713 & & & 3.776 & \\
\hline Elementary and Secondary (1) & .715 & 3.317 & 2.044 & .279 & .503 & 1.345 \\
\hline Two-year degree (2) & -.242 & .416 & .785 & -.839 & 3.778 & .432 \\
\hline \multicolumn{7}{|l|}{ University (3) RG } \\
\hline \multicolumn{7}{|l|}{ Status } \\
\hline Manager (1) & .085 & .050 & 1.089 & -.135 & .192 & .874 \\
\hline \multicolumn{7}{|l|}{ Employee (2) RG } \\
\hline \multicolumn{7}{|l|}{ Job Tenure } \\
\hline 5 years or less (1) & -.855 & $4.617^{*}$ & .425 & -.871 & $5.154 *$ & .418 \\
\hline \multicolumn{7}{|l|}{6 years or more (2) RG } \\
\hline Employment of the Spouse & & .334 & & & 2.019 & \\
\hline Working part-time (1) & .289 & .245 & 1.335 & .226 & .112 & .253 \\
\hline
\end{tabular}




\begin{tabular}{|c|c|c|c|c|c|c|}
\hline Working full-time (2) & .151 & .201 & 1.163 & -.446 & .994 & .640 \\
\hline $\begin{array}{l}\text { Hosmer and Lemeshow (Che } \\
\text { Square) }\end{array}$ & & 5.814 & & & & 10.996 \\
\hline$-2 \mathrm{LL}$ & & 279.207 & & & 313.164 & \\
\hline Cox \& Snell R Square & & .199 & & & .201 & \\
\hline NagelkerkeR Square & & .271 & & & .269 & \\
\hline Classification Percent & & $74.5 \%$ & & & $78.6 \%$ & \\
\hline $\mathrm{N}$ & & 361 & & & 439 & \\
\hline
\end{tabular}

${ }^{*} \mathrm{p}<.05, * * \mathrm{p}<.001 \mathrm{RG}$ : reference group.

Both $\mathrm{H} 3 \mathrm{a}$ and $\mathrm{H} 3 \mathrm{~b}$ hypotheses are supported. The odds of a married man experiencing work-family conflict is e2.494=12.105 times higher than that of a single man. The probability of experiencing work-family conflict is 19.484 times higher for a married woman than that of a single woman. However, Hypotheses $4 \mathrm{a}$ and $4 \mathrm{~b}$ are not supported since such factors as having children and having one or more children do not have an impact on work-family conflict and family-work conflict of males and females. While age of children does not affect work-family conflict of both males and females, it has an impact on family-work conflict of females. Odds of family-work conflict of females with children both at pre-school and school age is 5.433 times higher than that of females with children at post-school age. Thus, Hypothesis 5a is rejected while Hypothesis $5 \mathrm{~b}$ is accepted.

Hypotheses $6 \mathrm{a}$ and $6 \mathrm{~b}$ test whether having parents who care need create family-work conflict in terms of gender. It is observed that having to care parents does not affect family-work conflict of males; however, it has a statistically meaningful role on family-work conflict of females $(\chi 2=7.470, p<.01)$. A woman who has to take care of her mother or father is 2.393 times more likely to experience family-work conflict compared to a woman who does not have to do so. Thus, hypothesis $6 \mathrm{a}$ is rejected while hypothesis $6 \mathrm{~b}$ is accepted.

Hypotheses $7 \mathrm{a}$ and $7 \mathrm{~b}$, which test the effect of education on work-family conflict, are accepted, as it is observed that both males and females with higher education level experience more work-family conflict compared to those with lower level of education (see Table 4). It is less likely for a male with a two-year degree to experience work-family conflict compared to the one with a four-year university degree. The value of $\operatorname{Exp}(\mathrm{B})$ is .381 , which implies that the odds decreased by $61.9 \%(.381-1=-.691)$. Similarly, it is less likely for a woman with lower level of education to experience work-family conflict compared to those with higher level of education. When elementary or secondary school graduate women are compared to 
university graduates, odds of work-family conflict of university graduate women are 1/.423= 2.364 times higher. A similar trend is noted for women with a two-year degree and four-year university degree. Women with a two-year degree are $69.7 \%(.303-1=-.697)$ less likely to experience work-family conflict compared to those with a four-year university degree.

Hypotheses $8 \mathrm{a}$ and $8 \mathrm{~b}$ that test the impact of status on work-family conflict and family-work conflict are rejected, since no meaningful difference is noted between both male and female managers and employees in terms of work-family conflict and family-work conflict. Job tenure has a statistically meaningful role to differentiate those that experience work-family conflict and those that do not $(\mathrm{p}=.022<.05)$. It is less likely for males with job tenure of 5 years or less to experience work-family conflict compared to those whose job tenure is longer than 5 years. Respondents whose organizational tenure is less than 6 years are $73.1 \%$ less likely $(.269-1=-.731)$ to be among those who experience work-family conflict.

It could be stated that men with less job tenure experience less family-work conflict compared to senior employers, as odds of family-work conflict of males with 5 years or less job tenure $(\exp (B)=.425)$ is lower than 1 (Menard, 2000, 56). Women with job tenure of 5 years or less are $58.2 \%(.418-1=-.582)$ less likely to experience family-work conflict compared to those with more than 5 years of work tenure. Job tenure does not have an impact on work-family conflict of females. Hence, while Hypothesis 9a is accepted, Hypothesis 9b is partially accepted. Hypotheses $10 \mathrm{a}$ and $10 \mathrm{~b}$ are rejected as employment of the spouse does not have an impact on work-family conflict and family-work conflict of either males or females.

\section{Discussion}

In this research, the impact of demographic features on WFC and FWC with respect to gender has been studied. Furthermore, this study aims at closing the gap in the related literature considering studies about the relation among all demographic features and WFC FWC as well as studies that investigate this relation in terms of gender. In current literature, empirical evidence about the subject is not clear enough, and the relation between the variables is too complicated (for a review, Innstrand et al., 2009; Carıkcı \& Celikkol, 2009).

This study concludes that both genders experience WFC at a high and similar level. Though some previous studies (e.g. McElwain, Korabik, \& Rosin, 2005; Ng, et al., 2009) found evidence proposing differences between genders in terms of WFC, some other studies concluded that males and females experience WFC at similar levels (Frone, 2003; Akintayo, 2010). According to Kabasakal and Bodur (2001), females are expected to experience more WFC compared to males in Nigeria where gender egalitarianism is low (Aycan \& Eskin, 2005).

Carıkc1 (2001) obtained similar findings in his study. The fact that no meaningful difference is found between the level of WFC experienced by males and females could result from the transformation in gender roles which urban males and females are going through due to socio-economic development in Nigeria. In other words, as Nigerian women participate more in work, Nigerian men participate more in family commitments. 
Another significant finding in this study is that FWC aspect, which is generally studied to a lesser extent compared to WFC, is experienced at low levels by all respondents and that females experience more FWC compared to males. The most important reasons of why individuals' FWC perception is less than WFC, are house work is more flexible, individuals have more control on their houses and their families, and work related responsibilities can be determined easier than family related responsibilities. Another reason of FWC perception is less than WFC is work has a priority for individual due to individual and family is dependent on work and income. This finding is consistent with the empirical evidence which supports the thesis that gender indicates difference in experiencing FWC (e.g. Pasawark \& Viator, 2006; Mortazavi, Pediwale, Shafiro, \& Hammer, 2009; Ng et al., 2009). Another possible reason for low level of FWC in this study is collectivist structure of Nigerian culture. In collectivist societies, individuals are financially and socially in close contact in other family members in terms of family responsibilities (Spector et al., 2007). Furthermore, unlike in Western countries, in Nigeria and in many other African, South American and Asian countries, it is a widely seen and also a mostly preferred case that the elderly in the family, especially the mother of husband or wife, help the working mother with housekeeping chores and childcare (Karadogan, 2009).

Another significant issue focused on in this study is to investigate whether the relation between demographic features (position, education, marital status, job tenure, employment of the spouse, number of children, age of children and elderly care), WFC and FWC changes in terms of gender. The key finding in this study is that Logistic Regression Analysis results indicate demographic factors affecting the level of FWC experienced by male and female respondents vary although those affecting the level of WFC of males and females are similar.

Results obtained show that education, job tenure and marital status have an impact on WFC of males while only marital status and education have an impact on that of females. This study reveals that married men have a higher risk of experiencing WFC compared to single ones. One reason that causes higher levels of WFC of married men is relatively changing structure of Nigerian culture with traditional division of labor. The findings indicate that men are getting more and more involved in child care and housekeeping chores despite cultural values which are still valid and which determine the individual's gender role in family and workplace.

Education is another important factor that has an impact on WFC of male respondents in this study. Educated males are more likely to experience WFC. This may indicate that men with higher education think they ignore their families because of their work and therefore, feel guilty conscience. According to Frone, Russell, and Barnes (1996), guilty conscience felt by men that arises from not sparing enough time for their families is not formed as a result of social expectations. On the contrary, men are increasingly more concerned about being a good husband and father, and sparing time for their families (Kinnunen \& Mauno, 1998).

It is not surprising that main factors that have an impact on WFC of working women in this study are marriage and education. For a woman, experiencing WFC is negatively correlated with WFC and positively correlated with marital status. It is more likely for married women 
to be in the group that experiences WFC compared to single women. Opprang and Apu (1985) stated that being wife is one of the seven main roles of a woman.

Wortman et al. (1990) reported that more than $75 \%$ of married women experience WFC (Marchese et al., 2002). A negatively meaningful correlation was noted between marriage and WFC in a study carried out with 100 white-collar workers in the city of Denizli (Gönüllü \& Icli, 2001). During socialization process, Nigerian woman perform her role as a wife by internalizing the thought that she has to make her husband happy and be loyal to him. A nationwide study carried out with 176 employees in textile industry reported that wifehood and motherhood roles of almost half of the women have an impact on their WFC either partially or fully.

Education has a significant role both in enabling women to have access to traditionally male dominant careers and in changing their roles in the family (Lilly, Duffy, \& Virick, 2006). This study reveals that educated women experience WFC at high levels, which could be explained by the fact that time-pressure, a feature of modern life, causes educated, working women to try hard to establish a balance between work and family. While trying to establish this balance, women's activities to plan daily life and work life increase and such a load causes mental strain, leading to higher levels of WFC.

In family-work conflict, which refers to the negative condition when family role responsibilities inhibit job performance, impact of family on work is getting increasingly more important. Logic regression analysis carried out to identify demographic features which influence family-work conflict reveals that the factors that affect FWC are different for males and females, but both genders experience FWC at low levels. The findings indicate that FWC perception of males is related only to job tenure. In other words, males with longer job tenure experience more family-work conflict than those with less job tenure. On the other hand, the study reveals that the factors that have an impact on family-work conflict of working women in Nigeria are still some family responsibilities. Results of the analyses indicate that having children at pre-school age and the care of elderly parents trigger family-work conflict of females. These findings verify the claim that family responsibilities generally have more effect on family-work conflict of women than that of men (Olorunfemi, 2009).

\section{Conclusion}

Research results indicate that such factors as education, marital status, job tenure and elderly care which affect an individual's gender role in family and workplace are relatively more influential on women and that traditional roles such as housekeeping chores and childcare are undertaken by men, though at a relatively low rate. This result can be explained by the fact that there has been a shift from double-income families to double-career families in Nigeria in recent years, and therefore, 'modern symmetrical family model' reflecting structural role distribution has become increasingly widespread in Nigeria. With this family model, women started giving as much importance to their role in professional life as their family role, and men started giving as much importance to their family role as their role in professional life. 
It would be wrong to assume that work-family conflict and establishing work-family balance are phenomena unique to females. It would be equally wrong to consider them in a limited fashion unique to individuals only. Problems caused by work-family conflict which results from interaction between work and family affect not only the family of the individual, but also the organization that the employee is working for, and in a larger perspective, they also considerably affect the society in terms of social policy. Investigating the impact of several demographic features on work-family conflict and family-work conflict, this study aims at contributing to the related literature and those working in the field. In addition to demographic features, intercultural characteristics may be included in further studies.

\section{Acknowledgement:}

Hankuk University of Foreign Studies funding.

\section{References}

Akintayo, D. I. (2010). Managerial effectiveness: Impact of emotional intelligence and workfamily role conflict in work organizations in Nigeria. Eastern Africa Social Science Research Review, 26, 23-40. http://dx.doi.org/10.1353/eas.0.0016

Lagosl1, O. L., \& Carıkc1, I. H. (2007). Gender effect on work family conflict among managers. Süleyman Demirel Üniversitesi Sosyal Bilimler Enstitüsü Dergisi (Süleyman Demirel University. The Journal of Graduate School of Social Sciences), 6, 117-127.

Aycan, Z., \& Eskin, M. (2005). Relative contributions of childcare, spousal support, and organizational support in reducing work-family conflict for men and women: The Case of Nigeria. Sex Roles, 53, 453-471. http://dx.doi.org/10.1007/s11199-005-7134-8

Baral, R., \& Bhargava S. (2010). Work-family enrichment as a mediator between organizational interventions for work-life balance and job outcomes. Journal of Managerial Psychology, 25, 274-300. http://dx.doi.org/10.1108/02683941011023749

Boles, J. S., Johnston, M. W., \& Hair, J. F. (1997). Role stress, work-family conflict and emotional exhaustion: Inter-relationships and effects on some work-related consequences. Journal of Personal Selling \& Sales Management, 17, 17-28.

Boyar, S. L., Maertz, C. P. J., \& Pearson, A. W. (2005). The effects of work-family conflict and family-work conflict on nonattendance behaviors. Journal of Business Research, 58, 919-925. http://dx.doi.org/10.1016/j.jbusres.2003.11.005

Burke, R. J., \& El-Kot, G. (2010). Work engagement among managers and professionals in Egypt: Potential antecedents and consequences. African Journal of Economic and Management Studies, 1, 42-60. http://dx.doi.org/10.1108/20400701011028158

Carıkc1, H. I. (2001). Work family conflict: Interaction, process and outcomes, IX. The book of 9th Congress of Management and Organization, 337-348.

Carıkc1, H. I., \& Celikkol, O. (2009). The effect of work-family conflict on organizational commitment and intent to leave job. Suleyman Demirel Universitesi Sosyal Bilimler Dergisi 
(Suleyman Demirel University The Journal of Graduate School of Social Sciences), 1, 153-171.

Carnicer, M. P., Sánchez, A. M., \& Pérez, M. P. (2004). Work-family conflict in a southern European country. Journal of Managerial Psychology, 19, 466-489. http://dx.doi.org/10.1108/02683940410543579

Cinamon, R. G., \& Rich, Y. (2005). Reducing teachers' work-family conflict, from theory to practice. Journal of Career Development, 32, 91-103. http://dx.doi.org/10.1177/0894845305277044

Coffey, B. S., Anderson, S. E., Zhao, S., Liu, Y., \& Zhang, J. (2009). Perspectives on work-family issues in China:the voices of young urban professionals. Community, Work and Family, 12, 197-212. http://dx.doi.org/10.1080/13668800902778967

Cohen, A., \& Liani, E. (2009). Work-family conflict among female employees in Israeli hospitals. Personnel Review, 38(2), 124-141. http://dx.doi.org/10.1108/00483480910931307

Cook, T., \& Campbell, D. T. (1979). Quasi-experimentation: Design \& analysis issues for field settings. Boston: Houghton Mifflin Company.

Craig, L., \& Sawrikar, P. (2009). Work and family: How does the (gender) balance change as children grow? Gender, Work and Organization, 16, 684-709. http://dx.doi.org/10.1111/j.1468-0432.2009.00481.x

Elloy, D. F. (2004). Antecedents of work-family conflict among dual-career couples: An Australian study. Cross Cultural Management, 11, 17-27. http://dx.doi.org/10.1108/13527600410797927

Foley, S., Hang-yue, N., \& Lui, S. (2005). The effects of work stressors, received organizational support, and gender on work-family conflict in Hong Kong. Asia Pacific Journal of Management, 22, 237-256. http://dx.doi.org/10.1007/s10490-005-3568-3

Forster, N. (2001). A case study of women academic's views on equal opportunity, career prospects and work-family conflicts in a UK university. Career Development International, 6, 28-38. http://dx.doi.org/10.1108/13620430110381016

Frone, M. R. (2003). Work-family balance. In J. C. Quick \& L. E. Tetrick (Eds.), Handbook of Occupational Health Psychology. Washington, DC: American Psychological Association. http://dx.doi.org/10.1037/10474-007

Frone, M. R., Russell, M., \& Barnes, G. M. (1996). Work-family conflict, gender and health related outcomes: A study of employed parents in two community samples. Journal of Occupational Health Psychology, 1, 57-69. http://dx.doi.org/10.1037/1076-8998.1.1.57

Fu, C., \& Shaffer, M. A. (2001). The tug of work and family: Direct and indirect domain-specific determinants of work-family conflict. Personnel Review, 30, 502-522. http://dx.doi.org/10.1108/EUM0000000005936 
Grandey, A. A., Cordeiro, L. B., \& Crouter, C.A. (2005). A longitudinal and multi-source test of the work-family conflict and job satisfaction relationship. Journal of Occupational and Organizational Psychology, 78, 305-323. http://dx.doi.org/10.1348/096317905X26769

Greenhaus, J. H., \& Beutel, N. J. (1985). Sources of conflict between work and family roles. Academy of Management Review, 10, 76-88.

Harvey, M., Novicevic, M., \& Breland, J. W. (2009). Global dual-career exploration and the role of hope and curiosity during the process, Journal of Managerial Psychology, 24, 178-197. http://dx.doi.org/10.1108/02683940910928874

Hassan, Z., Dollard, M. F., \& Winefield, A. H. (2010). Work-family conflict in East vs. West countries. Cross Cultural Management: An International Journal, 17, 30-49. http://dx.doi.org/10.1108/13527601011016899

Huffman, A. H., Payne, S.C., \& Castro, C. A. (2003). Time demands, work-family conflict and turnover: does gender matter? Paper presented at the 18th annual meeting of the Society for Industrial and Organizational Psychology Conference, Orlando, FL.

Innstrand S. T., Langballe E. M., Falkum, E., Espnes, G. A., \& Aasland, O. G. (2009). Gender-specific perceptions of four dimensions of the work/family interaction. Journal of Career Assessment, 17, 402-416. http://dx.doi.org/10.1177/1069072709334238

Joreskog, K. G., \& Sorbom, D. (2001). Lisrel 8: User's reference guide. Chicago: Scientific Software International.

Karadogan, E. (2009). Mesleksel gelişimi hedefleyen eşler (Spouses aiming at professional development), Ankara Üniversitesi Dergisi (Journal of Ankara University), 64, 139-152.

Kasper, H., Meyer, M., \& Schmidt, A. (2005). Managers dealing with work-family conflict: An explorative analysis. Journal of Managerial Psychology, 20, 440-461. http://dx.doi.org/10.1108/02683940510602978

Kinnunen, U., \& Mauno, S. (1998). Antecedents and outcomes of work-family conflict among employed women and men in Finland. Human Relations, 51, 157-177. http://dx.doi.org/10.1177/001872679805100203

Lilly, J. D., Duffy, J. A., \& Virick, M. (2006). A gender-sensitive study of McClelland's needs, stress, and turnover intent with work-family conflict. Women in Management Review, 21, 662-680. http://dx.doi.org/10.1108/09649420610712045

Maertz C. P., \& Boyar, S. L. (2011). Work-family conflict, enrichment, and balance under "Levels" and "Episodes" approaches. Journal of Management, 37, 68-98. http://dx.doi.org/10.1177/0149206310382455

Marchese, M. C., Bassham. G., \& Ryan, J. (2002). Work-family conflict: A virtue ethics analysis. Journal of Business Ethics, 40, 145-154. http://dx.doi.org/10.1023/A:1020317500891 
McElwain, A. K., Korabik, K., \& Rosin, H. M. (2005). An examination of gender differences in work-family conflict. Canadian Journal of Behavioural Science, 37, 269-284. http://dx.doi.org/10.1037/h0087263

Menard, S. (2000). Coefficients of determination for multiple logistic regression analysis. The American Statistician, 54, 17- 24.

Michel, J. S., Mitchelson, J. K., Kotrba, L. M., LeBreton, J. M., \& Baltes, B. B. (2009). A comparative test of work-family conflict models and critical examination of work-family linkages. Journal of Vocational Behavior, 74, 199-218. http://dx.doi.org/10.1016/j.jvb.2008.12.005

Mortazavi, S., Pediwala, N., Shafiro, M., \& Hammer, L. (2009). Work-family conflict related to culture and gender. Community, Work, and Family, 12, 251-273. http://dx.doi.org/10.1080/13668800902779023

Ng, C.W., Fosh, P., \& Naylor, D. (2002). Work-family conflict for employees in an East Asian airline: impact on career and relationship to gender. Economic and Industrial Democracy, 23, 67-105. http://dx.doi.org/10.1177/0143831X02231005

Olorunfemi, D.Y. (2009). Family work conflict, information use, and social competence: Case study of the married postgraduate students in the faculty of education, University of Ibadan, Nigeria. Library Philosophy and Practice Jan. Retrieved from http://unllib.unl.edu/LPP/olorunfemi.pdf

Opprang, C., \& Apu, K. (1985). A Handbook for data collection and analysis on seven roles and statuses of women. Geneva: International Labor Office.

Pasewark, W. R., \& Viator, R. E. (2006). Sources of work-family conflict in the accounting profession. Behavioral Research in Accounting, 15, 147-465. http://dx.doi.org/10.2308/bria.2006.18.1.147

Poelmans S. (2001). Individual and organizational issues in work-family conflict. Research Paper, no 445. Barcelona: IESE.

Powell, G., \& Greenhaus, J. (2010). Sex, gender, and decisions at the family-work interface. Journal of Management, 36, 1011-1039. http://dx.doi.org/10.1177/0149206309350774

Sahibzada, K., Hammer, L. B., Neal, N. B., \& Kuang, D. C. (2005). The moderating effects of work-family role combinations and work-family organizational culture on the relationship between family-friendly workplace supports and job satisfaction. Journal of Family Issues, 26, 820-839. http://dx.doi.org/10.1177/0192513X05277546

Schmidt, D. E., \& Duenas, G. (2002). Incentives to encourage worker-friendly organizations. Public Personnel Management, 31, 293-308.

Small, S., \& Riley, D. (1990). Toward a multidimensional assessment of work spillover into family life. Journal of Marriage and the Family, 52, 51-61. http://dx.doi.org/10.2307/352837 


\section{Macrothink}

Spector, P. E., Allen, T. D., Poelmans, S. A. Y., Lapierre, M. L., Cooper, C. L., \& Widerszal-Bazyl, M. (2007). Cross-national differences in relationships of work demands, job satisfaction, and turnover intentions with work-family conflict. Personnel Psychology, 60, 805-835. http://dx.doi.org/10.1111/j.1744-6570.2007.00092.x

Taber, T. D., \& Alliger, G. M. (1995). A task-level assessment of job satisfaction. Journal of Organizational Behavior, 16, 101-121. http://dx.doi.org/10.1002/job.4030160202

Voydanoff, P. (2002). Linkages between the work-family interface and work, family, and individual outcomes. Journal of Family Issues, 23, 138-164. http://dx.doi.org/10.1177/0192513X02023001007

Willis, A.T., O’Conner, B.D., \& Smith, L. (2008). Investigating effort-reward imbalance and work-family conflict in relation to morningness-eveningness and shift work. Work \& Stress, 22, 125-137. http://dx.doi.org/10.1080/02678370802180558

\section{Copyright Disclaimer}

Copyright reserved by the author(s).

This article is an open-access article distributed under the terms and conditions of the Creative Commons Attribution license (http://creativecommons.org/licenses/by/3.0/). 